\title{
Aplikasi Perpustakaan On-line: (Kajian Awal Layanan On-line Perpustakaan Perguruan Tinggi Menggunakan Aplikasi Go-jek(C)
}

\author{
Syukron*
}

\begin{abstract}
Library is an information resource centre that provides intangible services. Library is also known as a not-for-profit-organization that provides places for reading. Libraries in Indonesia have not been professionally administered. But now library institutions at all levels, including those at the academic institutions, begin to revamp, continue the scientific tradition, develop the nation's civilization to save and store book collection in various subjects and languages with the help if information and communication technologies (ICT). The study explores the potentials that can be collaborated between library services and its information strength and the networked application such go-jek. The author identified the correlation between go-jek application model and academic library services. The study showed there was mutual need for both sides that could be collaborated.
\end{abstract}

Keywords : library services, go-jek application, collaboration, academic libraries

*) Staf Sekretariat, Kemenag Kota Jakarta Pusat

\section{A. PENDAHULUAN}

1. Perpustakaan dan e-Service

Aneka layanan serba elektronik yang dicanangkan secara resmi oleh negara dengan program e-government, seperti e-pajak, ebugdeting, e-purchasing, hal ini semakin meneguhkan bahwa perubahan terus terjadi. Ujian sekolah telah dilaksanakan berbasis internet, sehingga soal sudah ada di dalam bentuk digital. Pendaftaran dan penerimaan mahasiswa baru dilakukan di rumah, pemesanan tiket baik kendaraan darat, laut dan udara bisa di klik dari pelosok dengan bantuan handphone. Indonesia yang amat luas sangat diuntungkan dengan perkembangan teknologi informasi dan komunikasi post-moderen saat ini. Termasuk tidak ketinggalan, program $e$ library yang telah meramaikan khasanah dunia maya perpustakaan di Indonesia.

Kreatifitas anak bangsa juga menjadi terdorong, penjualan online tengah digandrungi dan diiklankan setiap hari di televisi, media sosial dan internet. Fasilitas menggunakan ujung jari, maka transaksi terjadi dalam hitungan menit, real time, dan pengirimannya dipantau, sehingga resah dan gelisah dapat dihindari, bahkan jika barang tidak sesuai opsi pembayaran akan dibatalkan. Hal ini tidak terjadi di perkotaan saja, berangsur-angsur menuju pelosok. Perubahan semakin mungkin karena dunia yang terkoneksi menjadi seperti small village. Jasa pengiriman dalam bidang bisnis menjadi semakin sibuk. Kreatifitas anak bangsa terus berlanjut misalnya layanan aplikasi ojek online yang sempat menjadi perdebatan diantara aspek legal dan pembelaan terhadap ekonomi kerakyatan, sebagai sumber mata pencaharian masyarakat kecil.

Melihat fenomena perkem-bangan aplikasi yang telah dimanfaatkan secara pribadi melalui handphone pintar (smartphone) yang telah menjadi sarana marketing, dan lahan pekerjaan baru. Tulisan ini bertujuan untuk mengintegrasikan aplikasi berupa rancangan dan analisa sederhana pelayanan perpustakaan online di perguran tinggi. Contoh rancangan dan analisa pemanfaatan jasa pengiriman online, on demand, dan real time misalnya dengan aplikasi ojek online Go-jek.

\section{Perumusan Masalah}

Agar penelitian ini terarah dan sesuai dengan goal (tujuan) yang hendak dicapai maka diperlukan suatu rumusan masalah. Adapun rumusan masalah yang akan menjadi kajian penelitian ini adalah :

1. Bagaimana layanan go-jek tersebut bersinggungan dan dapat dimanfaatkan sebagai layanan perpustakaan? 
2. Bagaimana skema dan rancangan layanan perpustakaan menggunakan aplikasi gojek?

\section{B. PEMBAHASAN}

\section{Perpustakaan dalam Jaringan (online)}

Produk fisik (telepon, faximili, atau komputer) dapat memberikan dukungan layananan yang semakin baik. Perpustakaan telah memanfaatkan alat bantu teknologi informasi yang sangat membantu pekerjaan perpustakaan yaitu komputer. Penggunaan komputer telah digunakan oleh perpustakaan sejak tahun 60 -an. Tahun tersebut menjadi awal bagi otomasi perpustakaan di negara maju seperti Amerika dan Eropa. Saat ini dengan internet memudahkan orang untuk mengakses perpustakaan dengan memanfaatkan perpustakaan daring (online)

Komputer dalam perkembangannya telah membantu pekerjaan seseorang tidak terkecuali di lingkungan perpustakaan. Komputer dapat digunakan untuk mengolah bahan pustaka dan temu kembali informasi dokumen. Komputer dapat menampung informasi mengenai koleksi tanpa memerlukan banyak tempat. Dengan cara tertentu informasi yang diperlukan akan terpapar pada layar komputer, informasi yang ditampilkan dapat digunakan untuk OPAC (Online Public Access Catalog). Perangkat lunak yang banyak digunakan dan diperkenalkan di Indonesia yaitu Computer Documentation Service/Integrated Service Information System(CDS/ISIS)*.

Pemanfaatan internet di Indonesia dipelopori oleh kalangan mahasiswa, utamanya dari Institut Teknologi Bandung (ITB) yang belajar di luar negeri. Tahun 1995-1997 - setelah kembali- mereka membentuk forum komunikasi berupa mailing list. Kemudian tahun 1994 forum tersebut membentuk Computer Network Research Group (CNRG), merupakan jaringan Internet yang diperuntukkan bagi pendidikan. Istilah perpustakaan digital di Indonesia dimunculkan tahun 1999 oleh salah satu elemen CNRG yaitu Knowledge Managemant Research Group (KMRG). Perpustakaan digital hasil KMRG telah digunakan untuk perpustakaan ITB dengan alamat $h t t p: / / w w w$.digilib.itb.ac.id dan program tersebut dapat dimiliki secara umum.

Kelompok kedua (dalam pengembangan internet dan program digitalisasi) dilakukan oleh pemerintah, misalnya dalam bentuk Warung Informasi Teknologi (Warintek). Inisiatif pemerintah (melalui PDII-LIPI) ini antara lain bermuatan pendidikan dan penyebaran teknologi tepat guna. Kelompok ketiga juga masih inisiatif dari pemerintah oleh Kementerian Perhubungan dan Telekomunikasi dalam bentuk elektronic government (egovernment) dengan proyek Nusantara 21. Kelompok keempat dibedakan dari isi dan topik, yaitu usaha digitalisasi dalam bidang seni-budaya (art), misalnya Surabaya Heritage yang dikelola oleh Universitas Petra Surabaya, atau digitalisasi koleksi lontar yang dilakukan oleh Perpustakaan Nasional Republik Indonesia.

Perpustakaan dalam pelayanannya dibagi dua yaitu layanan teknis dan layanan pemakai. Komunikasi terbesar pada layanan pemakai, terdiri dari: sirkulasi, layanan baca dan permintaan tertentu misalnya usulan koleksi, penelusuran informasi, permintaan kliping, dan permintaan bebas pustaka. Secara manual perpustakaan menyediakan lembaran formulir bagi pemustaka agar kebutuhannya dapat dipenuhi. Lembaran ini diolah oleh petugas. Usulan koleksi akan menjadi salah satu rujukan dalam pengadaan koleksi perpustakaan. Pustakawan mencarikan sumber informasi sesuai kebutuhan dengan koleksi dan relasi pada sumber informasi. Interaksi lainnya yaitu pendidikan pemakai, berita, dan peraturan perpustakaan.

Layanan perpustakaan khususnya perpustakaan Perguruan Tinggi dilihat dari segi pemakainya yaitu mahasiswa yang berada dalam kultur ilmiah, pemikirannya terpola secara kritis. Perpustakaan juga mengemban tugas melaksanakan Tri Dharma Perguruan Tinggi. Layanan yang semula berbasis tradisional, serba manual, lambat laun terintegrasikan melalui alat bantu teknologi informasi dan komunikasi (TIK) sebagai bentuk pelayanan prima. Di bagian bawah terdapat skema sederhana layanan perpustakaan yang kini dapat diakses melalui sistem komputerisasi, dan dapat diakses melalui jaringan internet dengan kelebihan lebih interaktif dengan perintah klik di ujung jari pengguna.

Skema tabel 1 terdapat tujuan dari layanan pengguna secara manual. Seiring waktu yang menjadi sasaran diperluas dan dikembangkan 
pola layanannya oleh perpustakaan agar semakin lebih baik. Teknologi informasi dan komunikasi (TIK) memungkinkan perubahan dokumen cetak menjadi dokumen digital yang mudah dibagikan (shareable), mereduksi hambatan waktu, mengurangi tempat dan ruang simpanan, pengamanan koleksi lebih terjamin, dan sirkulasi lebih efisien.

Selain itu juga dari kaca mata bisnis, pemasaran produk menjadi lebih bergairah, menemui pelanggan hingga ke manca negara, dan menciptakan peluang pangsa pasar baru. Selain itu diseminasi informasi hasil kajian (skripsi, tesis dan disertasi) menjadi lebih luas, lebih masif dan tercatat (recorded).

Tabel 1. Contoh layanan pemakai perpustakaan yang diolah dari beberapa sumber

\begin{tabular}{|c|c|c|c|}
\hline No. & $\begin{array}{c}\text { Layanan } \\
\text { atau } \\
\text { permintaan }\end{array}$ & Berkas/media & Hasil capaian \\
\hline 1 & $\begin{array}{l}\text { Layanan } \\
\text { Keanggotaan }\end{array}$ & $\begin{array}{ll} & \text { Formulir } \\
\text { - } & \text { Data Pribadi, Foto }\end{array}$ & $\begin{array}{ll}\text { - } & \text { Kartu Anggota } \\
\text { - } & \text { Ket bebas pustaka } \\
- & \text { Kartu anggota antar } \\
\text { perpust (Kartu sakti, } \\
\text { dsb) }\end{array}$ \\
\hline 2 & $\begin{array}{l}\text { Layanan } \\
\text { sirkulasi }\end{array}$ & $\begin{array}{ll}\text { - } & \text { Dokumen/koleksi } \\
\text { - } & \text { Katalog cetak dan } \\
\text { noncetak } \\
\text { - } & \text { Meja layanan } \\
\text { - } & \text { Tool/alat bantu } \\
\text { pencatat } \\
\text { - } & \text { Tata kelola arus } \\
& \text { antrean } \\
\text { - } & \text { Tata kelola } \\
\text { pengerakan }\end{array}$ & 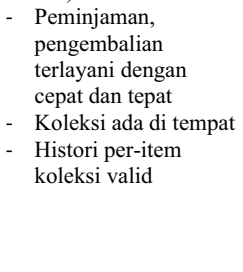 \\
\hline 3 & $\begin{array}{l}\text { Layanan } \\
\text { referensi }\end{array}$ & 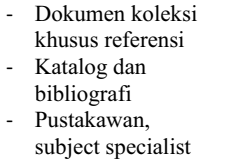 & $\begin{array}{ll}\text { - } & \text { Tersedianya dokumen } \\
\text { referral } \\
\text { - }\end{array}$ \\
\hline 4 & Usul koleksi & - Formulir terstruktur & $\begin{array}{l}\text { Data bibliografis dan } \\
\text { subyek koleksi } \\
\text { terdata, proses lebih } \\
\text { akurat } \\
\text { - Estimasi biaya akuisi } \\
\text { lebih valid }\end{array}$ \\
\hline 5 & $\begin{array}{l}\text { Pertanyaan } \\
\text { pemakai }\end{array}$ & $\begin{array}{ll}\text { - } & \text { Verbal/dialog } \\
\text { - } & \text { Form terstruktur } \\
\text { tertulis }\end{array}$ & $\begin{array}{l}\text { - } \text { Keluhan tertampung } \\
\text { - } \text { Bank pertanyaan dan } \\
\text { jawaban yang telah } \\
\text { tertulis ataupun } \\
\text { bersifat kasuistik } \\
\text { - } \\
\text { FAQ (Frequently } \\
\text { Asking Question) }\end{array}$ \\
\hline 6 & $\begin{array}{l}\text { Permintaan } \\
\text { jasa informasi } \\
\text { dan terbitan }\end{array}$ & $\begin{array}{ll}\text { - } & \text { Koleksi katalog } \\
\text { - } & \text { Kemas ulang } \\
& \text { informasi } \\
\text { - } & \text { Produksi ilmiah } \\
\text { - } & \text { Iklan pemasaran }\end{array}$ & $\begin{array}{ll}\text { - } & \text { Dokumen tersedia } \\
\text { - } & \text { Kliping dsb terjadwal } \\
\text { - } & \text { Terbitan buku dan } \\
& \text { jurnal terjadwal }\end{array}$ \\
\hline 7 & $\begin{array}{l}\text { Pinjam } \\
\text { koleksi antar } \\
\text { perpustakaan } \\
\text { (PAP) }\end{array}$ & $\begin{array}{ll}\text { - } & \text { Dokumen } \\
\text { - } & \text { MOU kerjasama } \\
\text { - } & \text { Proposal }\end{array}$ & $\begin{array}{ll}\text { - } & \text { Peminjaman } \\
\text { - } & \text { Ketersediaan } \\
\text { dokumen } \\
\text { - } \\
\text { Ikatan resmi, silang } \\
\text { layan perpustakaan, } \\
\text { tukar informasi } \\
\text { pustaka dsb }\end{array}$ \\
\hline 8 & $\begin{array}{l}\text { Pendidikan } \\
\text { pemakai }\end{array}$ & $\begin{array}{l}\text { - Katalog atau Opac } \\
\text { - Manual dan tanda } \\
\text { marka } \\
\text { - Teknik browsing } \\
\text { dan searching }\end{array}$ & $\begin{array}{l}\text { - Efektivitas } \\
\text { penggunaan } \\
\text { perpustakaan dan } \\
\text { koleksinya oleh users } \\
\text { - Melek informasi }\end{array}$ \\
\hline
\end{tabular}

Pustakawan sebagai profesi harus memiliki beberapa keterampilan antara lain:

\section{Adaptability}

Pustakawan dapat menyesuaikan keadaan yang menantang. Sudah saatnya adaptif memanfaatkan teknologi informasi. Pustakawan tidak lagi bersandar pada buku teks dan jurnal di rak, tetapi dengan memanfaatkan internet untuk mendapatkan informasi yang aktual.

\section{People Skills (Soft Skill)}

Pustakawan adalah mitra intelektual, mampu berkomunikasi baik lisan maupun tulisan. Hal ini dapat dikembangkan dengan membaca, mendengarkan aneka informasi, berkenalan dengan banyak orang, berorganisasi dan berusaha diaplikasikan dalam aktivitas sehari-hari.

\section{Berpikir Positif}

Pustakawan diharapkan menjadi seorang yang berpikiran positif sehingga jika dihadapkan pada pekerjaan besar dapat bersikap optimis

\section{Personal Added Value}

Pustakawan harus mempunyai nilai tambah tidak hanya ahli dalam mengindeks, mengkatalog, meng-adakan bahan pustaka, dan pekerjaan rutin lainnya. Nilai tambah misalnya tahu bagaimana cara cepat mancari informasi tertentu.

5. Berwawasan Enterpreneurship (Kewirausahaan)

Informasi adalah kekuatan, informasi bercost, maka pustakawan harus memulai wawasan enterpreneurship agar dapat bertahan. Perpustakaan secara perlahan harus menjadi income generation unit.

\section{Team Work-Sinergi}

Di dalam era global yang ditandai dengan ampuhnya internet dan membludaknya informasi, pustakawan tidak lagi bekerja sendiri, mereka harus membentuk team work untuk bekerja sama mengolah informasi.

\section{Aplikasi Go-Jek dan Layanan}

Go-jek, sebuah aplikasi yang dikembangkan oleh Perusahaan Go-Jek Indonesia, didirikan oleh seorang anak muda lulusan Hardvard University, bernama Nadiem Makarim. Usaha ini didirikan sekitar tahun 
2014, meskipun demikian layanan ojek online bukanlah yang pertama dalam soal aplikasi jemputan kendaraan. Namun demikian aplikasi Go-jek (selanjutnya ditulis AG) memiliki karakteristik yang unik. Keunikan layanan AG dibandingkan dengan aplikasi serupa adalah pengembangan kepada jenis layanan yang variatif.

Layanan AG terdiri dari layanan utama yaitu antar jemput, dikenal dengan istilah ojek, berbasis sepeda motor. Pengguna harus memiliki 1). perangkat telepon pintar dengan basis $i O S$ dan $O S$ Android, versi 4.0 atau di atasnya agar lebih stabil bagi si pengguna, 2). mengunduh AG yang disediakan oleh vendor melalui google play store, dan 3). memiliki paket data internet atau terkoneksi ke jaringan internet (via-wifi). Selain ojek, ketika pertama kali dilaunching AG memiliki empat menu layanan. Sesuai dengan motto dari AG yaitu 'an ojek for every need', layanan tersebut dapat disimak dalam caption gambar 2 dan gambar 3 :

\section{0- $-8 x$}

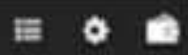

\section{GO $\nleftarrow$ JEK}

\section{PICX A SERVICE}

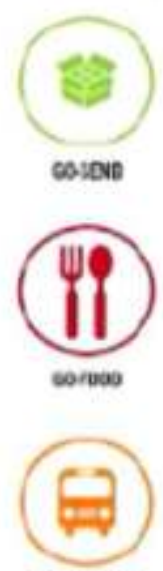

cotiswat

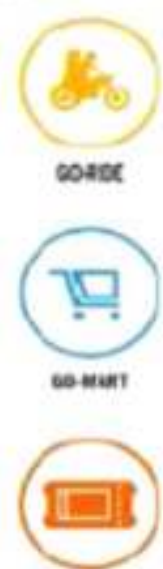

$\cos x$

menu aplkasi Gojek

Gambar 1 


\section{Cara pesan gojek:}

1. Pilihan : ojek dan Kurir

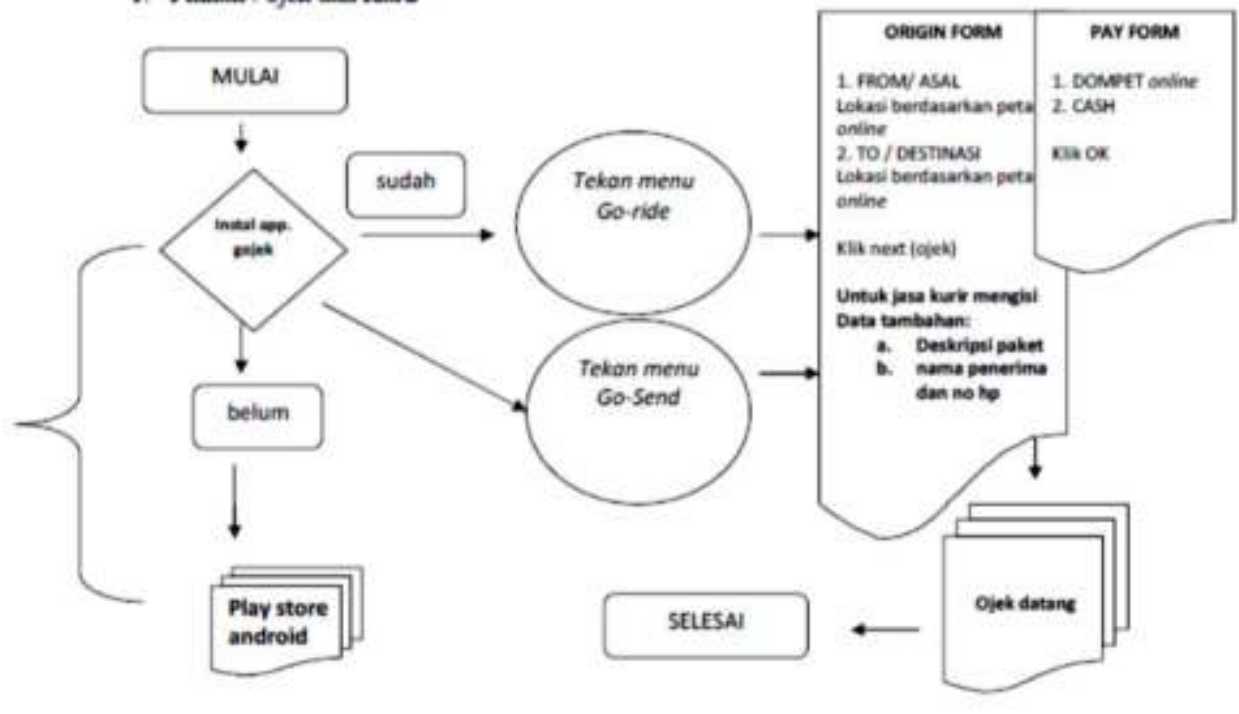

Gambar 5

2. Pullhan: go-mart dan go-food

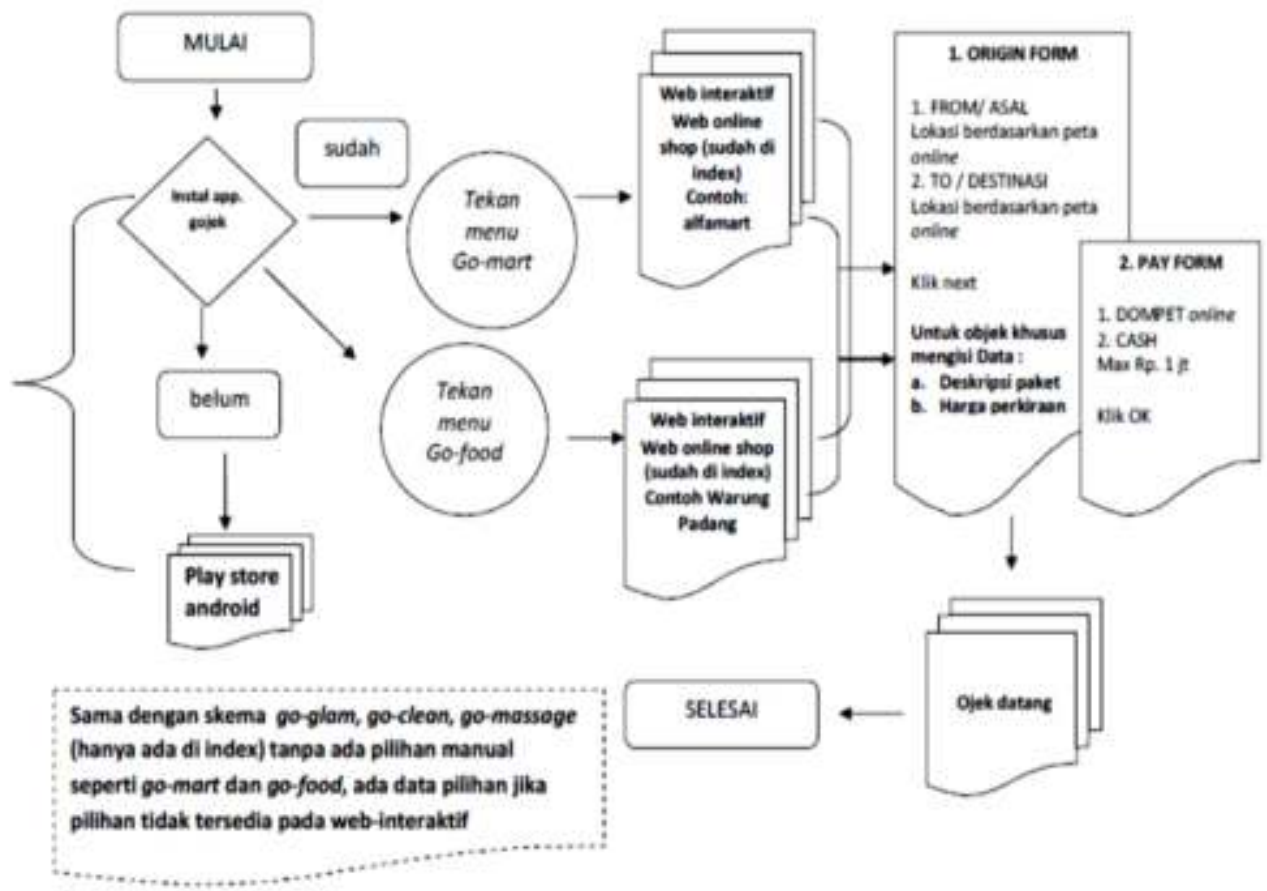

Gambar 6 
Gambar 6 AG memiliki menu dan teknis pemesanan via telepon seluler, dengan kerumitan berbeda, terutama pada pemesanan pihak ke-3, sebagaimana penjelasan berikut:

1. Origin field dan destination field, untuk pilihan dasar layanan antar ojek, pesan dari lokasi awal (titik jemput) menuju lokasi transit. Kedua field ini amat sangat bergantung dengan maps/peta yang menjadi bagian tak terpisahkan.

2. Pada bagian jasa pihak ke-3 akan terdapat form isian berjenjang 4-5 langkah (multi direction), menggunakan piramida terbalik, digiring untuk meperjelas item order kemudian mengisi form origin field dan destination field. Opsi pilihan item order untuk spesifikasi; harga, jumlah barang, jumlah tenaga (person) yang digunakan, skala waktu proses (jika pilihan go-clean, go-glam, dan go-massage).

3. Selain item order isian selanjutnya terakumulasi pada cost service; pertama, harga barang, kedua, harga untuk jasa pihak ke-3 dan ketiga, harga utama (paket ojek sebagai core bussiness)

4. Layanan pada menu go-send dapat berbentuk apa saja, termasuk buku koleksi perpustakaan dengan proses indexing di web interaktif go-jek tentunya. Pilihan gomart memungkinkan penjualan karya terbitan perpustakaan baik kliping, jurnal dsb.

5. Demikian halnya perpustakaan dapat memesan/pengadaan koleksi lewat jasa gojek dengan menu pilhan go-mart, diawali dengan memilih posisi toko buku, atau pesanan secara online dan diteruskan pembeliannya dengan kiriman ojek online.

6. User perpustakaan dapat mengisi form pilihan bebas terhadap jenis barang yang tidak terindeks, misalnya membeli jurnal perpustakaan dengan estimasi harga tertentu. a. Jenis Layanan AG :

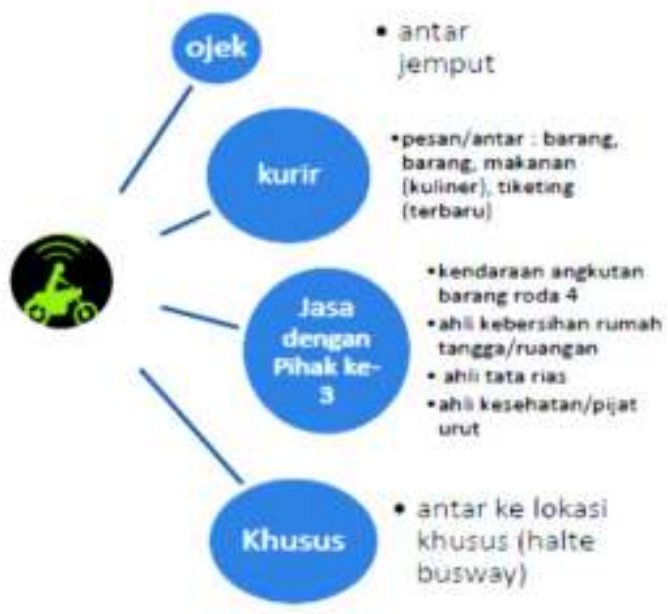

Gambar 7

Gambar 7 : AG terdiri 4 (empat) bagian utama yaitu layanan berkaitan dengan ojek, kurir, jasa dengan pihak ke-3 dan layanan khusus. Dapat dilihat bahwa skala lingkaran disesuaikan dengan prospek layanan yang amat sangat dibutukan dan diperlukan dan menjadi lahan bisnis. Masa depan go-jek berkembang dengan aneka layanan; jasa dengan pihak ke-3, dan kerjasama khusus (busway, penjual tiket online).

\section{b. Struktur Aplikasi dan Alur-Kerja AG :}

Gambaran mengenai struktur content aplikasi dari aplikasi go-jek dapat digambarkan sebagai berikut:

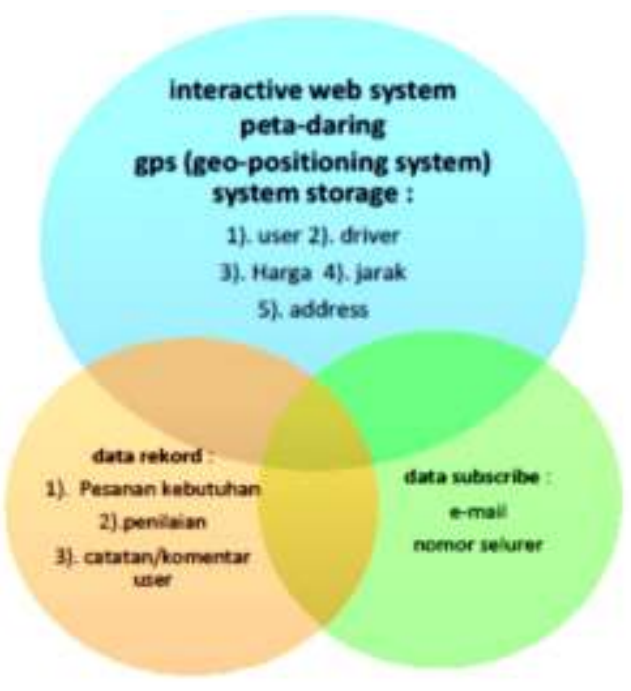

Gambar 8 


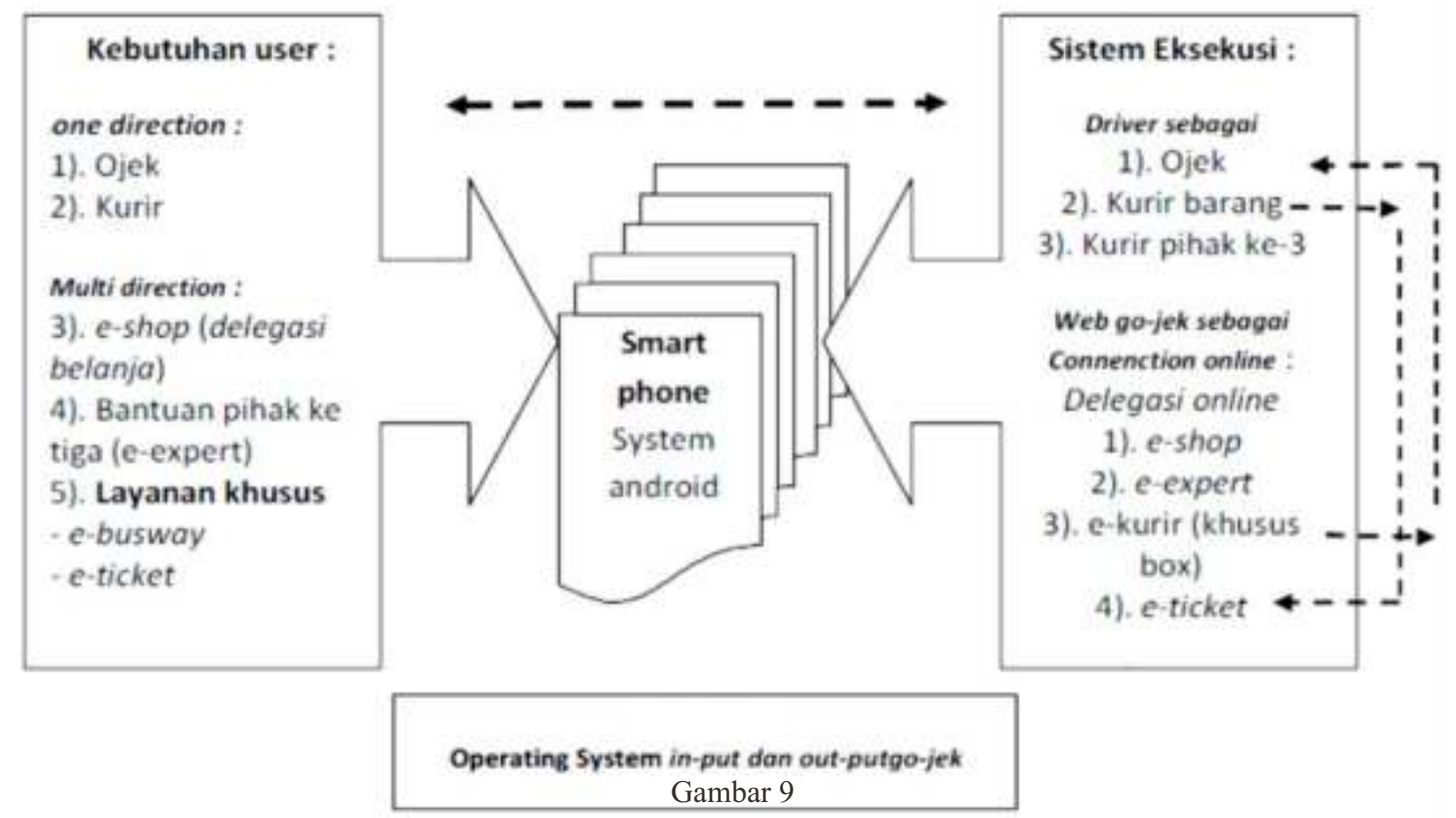

Gambar 9 merupakan penjelasan teori sistem, baik pesanan (input) dan hasil akhir (output) dari media telepon seluler user, database web go-jek interaktif dan telepon seluler driver go-jek. Lalu lintas data dikomunikasikan sedemikian rupa sehingga pesanan dari telepon seluler tersebut dapat terkoneksi, dieksekusi dengan tepat, dan dapat dilaksanakan oleh driver di lapangan. AG dengan pembagian berdasarkan step/langkah pemesanan, menu yang melibatkan pihak ke-3 lebih komplek; memerlukan jeda waktu, dan konsentrasi dari pemesannya langsung, karena jenis pilihan/kebutuhan yang telah tersedia (kerjasama bisnis dengan Go-jek) dan telah terindeks pada AG.

\section{SKEMA APLIKASI GO-JEK DAN LAYANAN PERPUSTAKAAN \\ 1. Sub-Ordinasi dari Layanan Go-jek}

Lahirnya model usaha go-jek secara tidak langsung beririsan dengan dunia informasi. Masa post-industrial identik dengan tumbuhnya ekonomi berbasis perangkat teknologi Informasi dan Komunikasi.
Teknologi merupakan hal yang tidak bisa lepas dari masyarakat modern saat ini. Semakin hari, perkembangan TIK yang terjadi berjalan massive, cepat dan komplek. Teknologi ibarat magnet yang tidak dapat dihindari. Perubahan tersebut menuntut manusia untuk peka terhadap teknologi informasi, hingga memunculkan apa yang disebut "masyarakat informasi”.

Pesatnya era ekonomi informasional ini memiliki dampak positif dan negatif. Positifnya adalah kegiatan perekonomian yang terjadi bukan hanya dalam lingkup regional tetapi sudah menglobal. Mendorong pelaku bisnis untuk lebih meningkatkan mutu dengan keunikan (berbeda dengan yang sudah ada) dari produk jasa yang dihasilkan. Akan tetapi dampak negatif dari ekonomi informasional akan ada, karena sifat teknologi yang bebas nilai, siapa saja dapat menggunakannya tanpa kecuali-- kasus perekrutan anggota teroris online, layanan 'mesum' online-- atau membuat pelaku bisnis yang tidak peka akan tersingkir secara perlahan dari persaingan yang sangat kompetitif. 


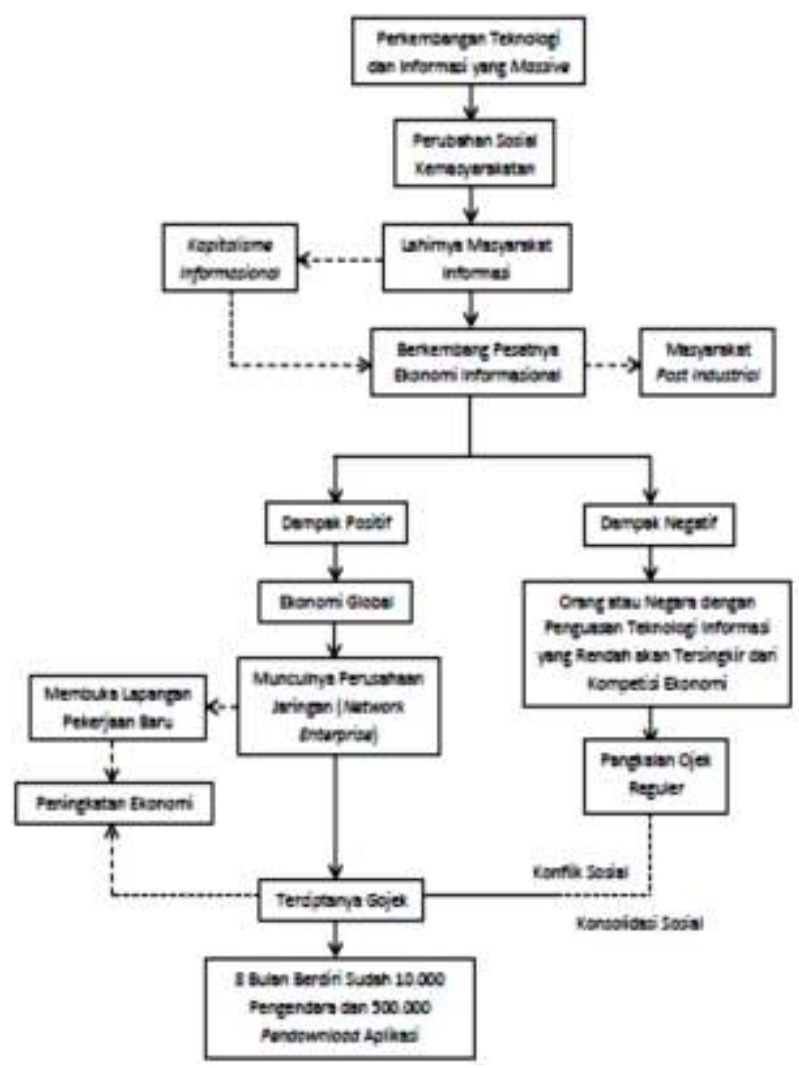

Gambar 10. Konstruksi Ekonomi Post Industrial oleh Anisa Dwi I. dan Zurotul Laili

Sub-ordinasi layanan AG yang dapat dilaksanakan melalui kerjasama dengan pelaku bisnis yang telah mapan seperti halnya Perusahaan go-jek. Gambaran skema layanan yang dapat disinergikan dapat dilihat pada tabel dibawah ini.

Tabel 3. Layanan Berbasis AG, hanya contoh sederhana

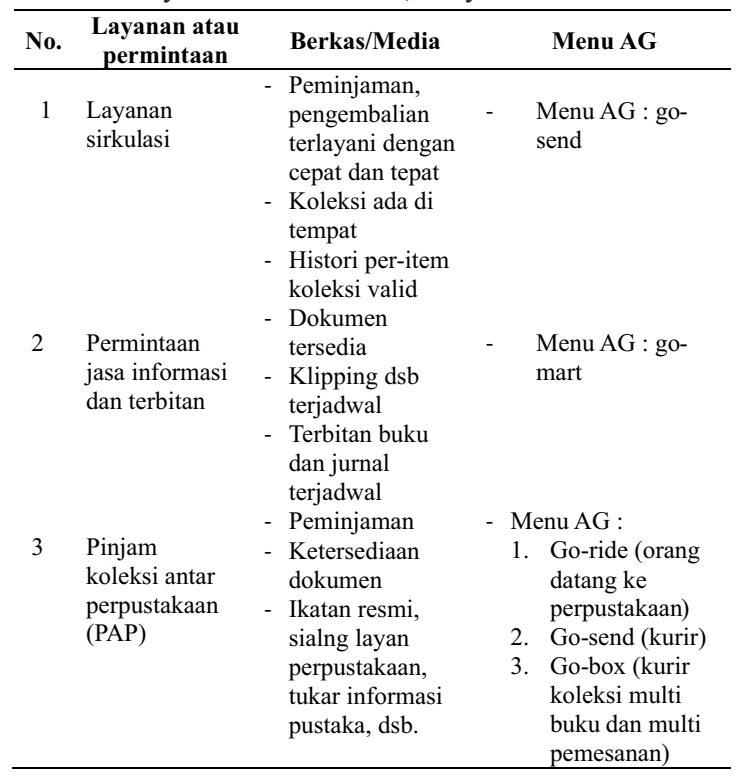

Tabel di atas menunjukkan layanan via-AG yang dapat dilakukan oleh perpustakaan. Karena bersifat sub-ordinasi, dari AG ini dapat diderivasi untuk layanan sirkulasi dengan memanfaatkan menu go-send dengan detil; apakah koleksi buku yang akan dipinjam, perpanjangan atau dikembalikan. Kedua, layanan pemasaran kemas ulang dan produk terbitan berupa buku, jurnal ilmiah, dan karya grey area melalui bantuan menu go-mart. Layanan pinjam antar instansi perpustakaan dengan tiga menu : go-ride, go-send, dan gobox. Kelebihan aplikasi tersebut, media antarmuka sudah sangat user friendly, lebih tepat menggiring kebutuhan user, catatan/record data lebih mudah, dan bersifat segera (real time).

Dengan sistem sub-ordinat ini, pustakawan hanya meminta rekord data layanan melalui email, sms, dengan pihak go-jek sebagai laporan. Kerjasama dengan penyelenggara jasa online dimaksud untuk memperluas pemasaran jasa perpustakaan dan bermuara pada peningkatan layanan. Tidak berlebihan jika seorang kepala UPT Perpustakaan Perguruan Tinggi di Surakarta dengan memberi definisi baru mengenai fungsi perpustakaan yang menurutnya, perpustakaan sebagai pusat sumber belajar dan ilmu pengetahuan harus menjadi pusat 'klinik' dan wisata pustaka ilmiah. Hal ini menjadi suatu harapan sebuah perpustakaan perguruan tinggi yang memiliki kekuatan koleksi pilihan, dan diorganisasikan lebih baik, dapat menjadi sumber solusi (problem solving) masalah ekonomi, sosial, budaya, hukum, dan fungsi lain dari perpustakaan menjadi tempat tujuan wisata ilmiah. Keunikan perpustakaan perguruan tinggi dengan mahasiswa yang kritis, kreatif, dan mempunyai aspek seni tata bangunan, taman, dan dekorasi koleksi sebagai bagian dari pelayanan prima, secara praktek, bukan hanya teori.

Jenis dan pemodelan sub-ordinasi sebenarnya dapat dilakukan dengan membuat sistem terintegrasi dari sub-sistem e-academic. Kelebihan lainnya yaitu akan memudahkan perguruan tinggi yang masih dalam tahap berkembang. Kerjasama ini patut menjadi perhatian dan dikembangkan dari waktu ke waktu. Kerjasama dengan perusahaan go-jek merupakan salah satu pilihan dari banyaknya kerjasama perpustakaan perguruan tinggi. Sehingga perlahan, akan semakin banyak yang 
bergabung, semakin memudahkan integrasi layanan antar perpustakaan di Indonesia, berbasis aplikasi.

\section{Layanan Mandiri dengan Model Aplikasi Go-jek}

Informasi merupakan kekuatan, informasi memiliki 'nilai', maka pustakawan harus sudah mulai berwawasan entrepreneurship agar dalam perjalanan sejarahnya nanti dapat bertahan. Perpustakaan secara perlahan harus menjadi berdaya saing, yaitu dengan memanfaatkan teknologi. Elaborasi ini dimungkinkan karena kecenderungan teknologi Internet of things (IoT). IoT, didefiniskan sebagai suatu keadaan terkoneksinya komunikasi manusia dengan benda-benda elektronik melaui jaringan internet. Opsi pertama dari pembahasan kajian ini kiranya menjadi hal yang paling mungkin dilaksanakan, yaitu berkolaborasi dalam jaringan go-jek. Kekurangan dari opsi kedua yakni pangsa pasar yang akan menjadi layanan library application system, sangat terbatas, dan memerlukan kajian yang lebih khusus karena biaya dan kelanggengan layanan tersebut.

Aplikasi mandiri dapat dikembangkan dengan manajemen go-jek atau dengan pihak internal. Pertimbangan dengan pengelolaan mandiri yakni data record menjadi mandiri dan tarif layanan lebih murah. Perpustakaan Perguruan Tinggi memiliki sumber daya teknologi informasi dengan kelompok kajian mahasiswa atau tim teknologi informasi. Contoh tabel. 4.1, penulis mengambil istilah library (lib) untuk setiap menu adaptasi proyek AG. "An Library-service to every need", motto yang dapat dijadikan brand untuk layanan perpustakaan berbasis android ini.

Tabel 4 menunjukkan tujuh bentuk menu yang dapat disediakan dari aplikasi Android Library Application. Tujuh (7) menu di atas berisi irisan dengan tabel 1 pada bagian pembahasan sebelumnya. Tujuan bagian menumenu layanan bersifat sangat teknis perpustakaan, dapat dikategorikan dengan multi direction dengan dua lapisan utama (lihat gabungan gambar 2 dan 3). Kerjasama dalam bidang data base telah banyak dilakukan oleh pusat kuliner, warung makan, resto, cafe, usaha kecil dan menengah (UKM), retail, butik, toko online dan telah dirasakan manfaatnya dengan bantuan perusahaan ojek online. Perpustakaan dapat memilih dan memilah dari tujuh bagian di atas, menyesuaikan dengan kebutuhan.

Tabel 4. Layanan library application system adaptasi aplikasi go-jek

\begin{tabular}{|c|c|c|}
\hline No. & Layanan/Permintaan & Keterangan \\
\hline 1 & Lib-subscribe & $\begin{array}{l}\text { Layanan jasa } \\
\text { keanggotaan }\end{array}$ \\
\hline 2 & Lib-cyrculate & $\begin{array}{l}\text { Layanan jasa sirkulasi } \\
\text { perpanjangan dan time } \\
\text { alert (jangka waktu } \\
\text { peminjaman, dan ada } \\
\text { peminjam lain) }\end{array}$ \\
\hline 3 & Lib-send dan lib-box & $\begin{array}{l}\text { Layanan jasa sirkulasi } \\
\text { peminjaman dan } \\
\text { pengembalian } \\
\text { anggota/mahasiswa } \\
\text { perpustakaan, lib-box } \\
\text { pengantaran via mobil }\end{array}$ \\
\hline 4 & Lib-searching & $\begin{array}{l}\text { Layanan jasa } \\
\text { penelusuran informasi, } \\
\text { layanan referensi, jasa } \\
\text { kliping media, kemas } \\
\text { ulang informasi }\end{array}$ \\
\hline 5 & Lib-research & $\begin{array}{l}\text { Layanan jasa } \\
\text { penyediaan karya tulis } \\
\text { grey literature (hasil } \\
\text { penelitian mahasiswa, } \\
\text { dan dosen) }\end{array}$ \\
\hline 6 & Lib-mart & $\begin{array}{l}\text { Layanan jasa pemasaran } \\
\text { dan penjualan terbitan } \\
\text { perpustakaan (buku, } \\
\text { jurnal dan katalog } \\
\text { (bibliografi), dan paket } \\
\text { informasi cetak dan non } \\
\text { cetak lainnya) }\end{array}$ \\
\hline 7 & Lib-loan & $\begin{array}{l}\text { Layanan jasa sirkulasi } \\
\text { peminjaman dan } \\
\text { pengembalian antar } \\
\text { perpustakaan }\end{array}$ \\
\hline
\end{tabular}

Perpustakaan memiliki sistem kerja dan hasil kerja berupa terbitan perpustakaan (buku, jurnal, bibliografi of bibliografi, klipping koran) secara bertahap diindeks dalam aplikasi go-jek untuk membantu para pencari informasi. Aneka koleksi buku yang menjadi kekuatan koleksi di perpustakaan dapat dipesan melalui aplikasi smartphone, kapan pun, di mana pun. Secara teknis, katalog online perpustakaan dapat terkoneksi dan terindeks dalam jaringan go-jek. Program ini lebih memungkinkan menjadi layanan khusus (lihat Tabel 2.5 pada menu go-bus --dengan transjakarta dan go-tik -dengan penjual tiket online) meskipun basis aplikasi telah terpisah namun dalam hal eksekusi dilapangan tetap bekerjasama dengan perusahaan go-jek dan atau yang sejenis. 
Kendala utama dari layanan mandiri (aplikasi buatan sendiri) tentu harus memilih skala prioritas, karena faktor penghambat yang cukup komplek. Kendala dari layanan real time seperti penyediaan armada kendaraan baik roda 2 (sepeda motor) dan roda 4 (mobil) untuk mengantar kebutuhan pemustaka. Selanjutnya adalah jaminan/garansi koleksi jika hilang, rusak (ringan, sedang, dan berat), koleksi tertukar, tentu membutuhkan aturan khusus. Ketiga, penetapan tarif jasa layanan yang membutuhkan legalisasi dari lembaga/ kementerian, diperlukan standard biaya umum (SBU) layanan perpustakaan oleh pemerintah atau lembaga profesi. Keempat, lingkup kewenangan layanan perpustakaan dihubungkan dengan lokasi user, hal ini membutuhkan kerjasama pertukaran informasi koleksi antar perpustakaan.

\section{KESIMPULAN}

Peran dan tanggungjawab seorang pustakawan menjadi salah satu tolok ukur kepuasan pengguna. Profesi pustakawan harus kreatif dalam rangka penyelenggaraan perpustakaan yang berorientasi pada kepuasan pemustaka informasi misalnya dengan kerjasama dan kolaborasi dengan go-jek. Pustakawan dituntut untuk memanfaatkan teknologi informasi dan komunikasi untuk kemajuan dan peningkatan pelayanan. Pustakawan juga memiliki kelemahan, misalnya larut dalam rutinitas, hanya bertumpu dengan mengelola informasi dan bahan pustaka yang dimiliki saja, kemudian menunggu pengguna yang datang. Demikian halnya perusahaan ojek online memiliki kekurangan perluasan usaha dan persaingan usaha. Sementara itu, layanan perpustakaan belum mendapat garapan serius dari pesaing usaha sejenis. Menjadi keniscayaan keduanya, baik go-jek dan perpustakaan perguruan tinggi untuk mengikat kerjasama yang saling menguntungkan bersama.

Pesatnya peredaran informasi membuat profesi pustakawan menjadi penting, misalnya melakukan pemasaran kemas-ulang (repackaging) informasi. Kedua, pustakawan harus mau bekerjasama dalam tim dan dengan profesi bidang lain (ahli IT, entrepreneur informasi). Pustakawan Perguruan Tinggi dapat melengkapi sarana perpustakaan dengan teknologi informasi yang mutakhir, yang dapat dijadikan alat pemasaran. Koneksi dalam jejaring maya melalui media sosial akan memperkuat posisi perpustakaan, akan tertinggal jika tidak ikut dalam kerjasama menghadapi perubahan. Kendala dalam pengelolaan perpustakaan harus segera ditemukan solusi untuk perbaikan sistem pengelolaan dan peningkatan kualitas sumber daya pustakawan yang profesional.

\section{DAFTAR PUSTAKA}

Anisa Dwi Istiningrum dan Zarotul Laili. "Laporan Penelitian : Tren Gojek dan Ruang Permasalahannya: Studi pada Perkembangan Smart Transportation Gojek di Kawasan Beji Kota Depok”. Jakarta, LPM-Jkt, 2015

Anonim, "Babak Baru Teknologi Informasi : Rubrik Teknologi Informasi” : Koran Kompas, Rabu 28 Oktober 2015

Ardhoyo, "Peran dan Strategi Humas (Public Relation) dalam Mempromosikan Produk Perusahaan": jurnal WIDYA : Vol 1 No. 1 MeiJuni, hal. 16. Jakarta : Univ. Moestopo Beragama, 2013

Onno W. Purbo. Filosofi Naif Kehidupan Dunia Cyber. Jakarta : Republika, 2000

Putu Laxman Pendit. "Inisiatif Penggunaan Perpustakaan Digital di Indonesia." Makalah Seminar Perpustakaan di Universitas Islam Negeri Syarif Hidayatullah Jakarta, 15 maret 2003.

\section{Internet}

http://www.digilib.unsri.ac.id/download/Profesiona lisme\%20Pustakawan.pdf, Gunawan, Hendry dan Novita Vitriana. Profesionalisme Pustakawan. Palembang : UPT Perpustakaan Sri Wijaya diakses tgl, 17 Pebruari 2016

https://id.wikipedia.org/Nadiem Makarim. diakses tgl, 16 Pebruari 2016

http:// www.go-jek.com, dikases tgl 15 Pebruari 2016. 